Ohio Wesleyan University

Digital Commons@ OWU

Student Symposium

Apr 25th, 5:50 PM - 6:10 PM

\title{
Size increase with altitude in the Rufous-collared Sparrow (Zonotrichia capensis)
}

Kyle Davis

Ohio Wesleyan University

Follow this and additional works at: https://digitalcommons.owu.edu/studentsymposium

Part of the Zoology Commons

Davis, Kyle, "Size increase with altitude in the Rufous-collared Sparrow (Zonotrichia capensis)" (2019). Student Symposium. 1. https://digitalcommons.owu.edu/studentsymposium/2019/panel_2c/1

This Presentation is brought to you for free and open access by the Student Scholarship at Digital Commons @ OWU. It has been accepted for inclusion in Student Symposium by an authorized administrator of Digital Commons @ OWU. For more information, please contact earutigl@owu.edu. 


\section{Size Variation with Altitude}

in the Rufous-Collared Sparrow

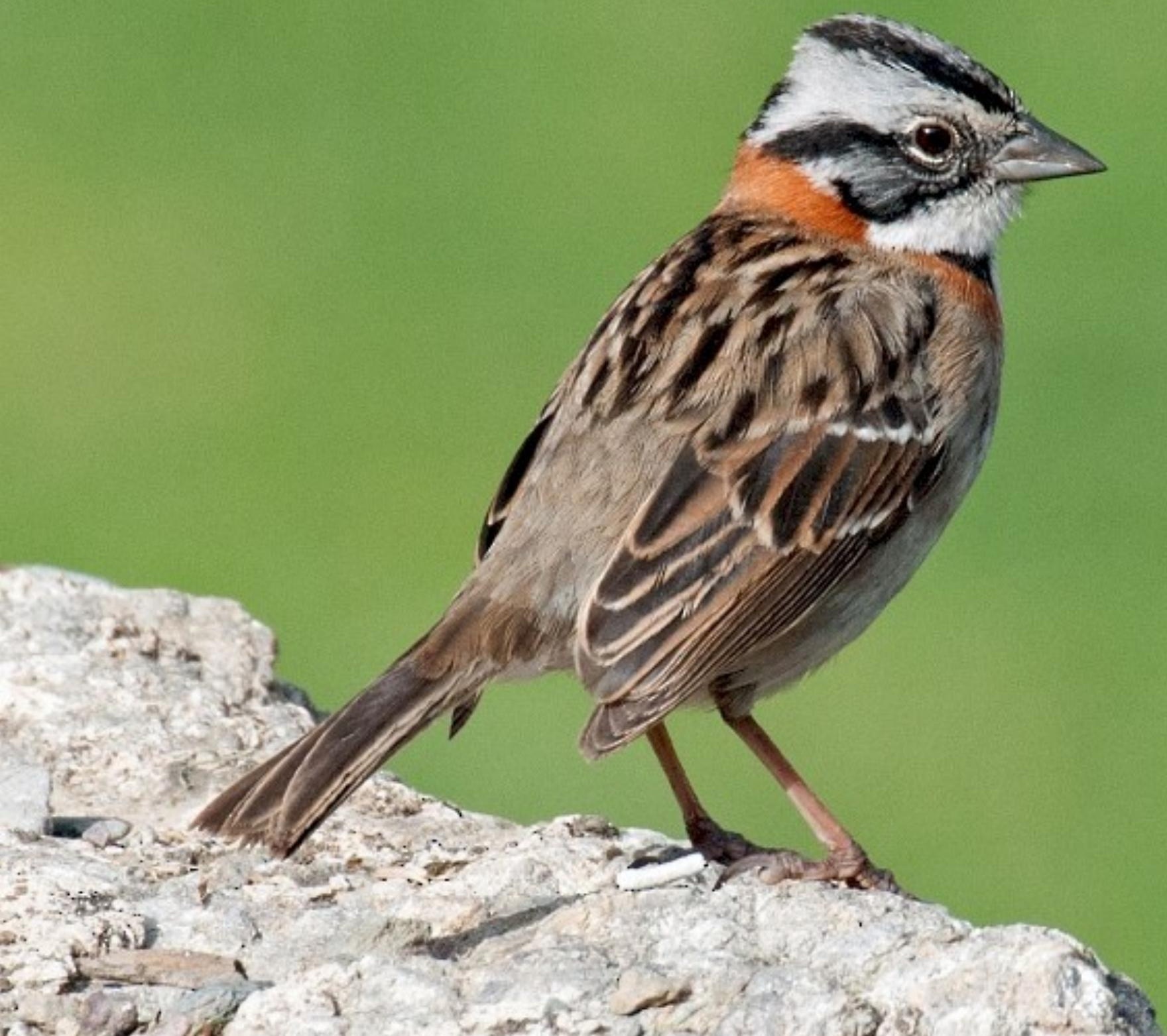




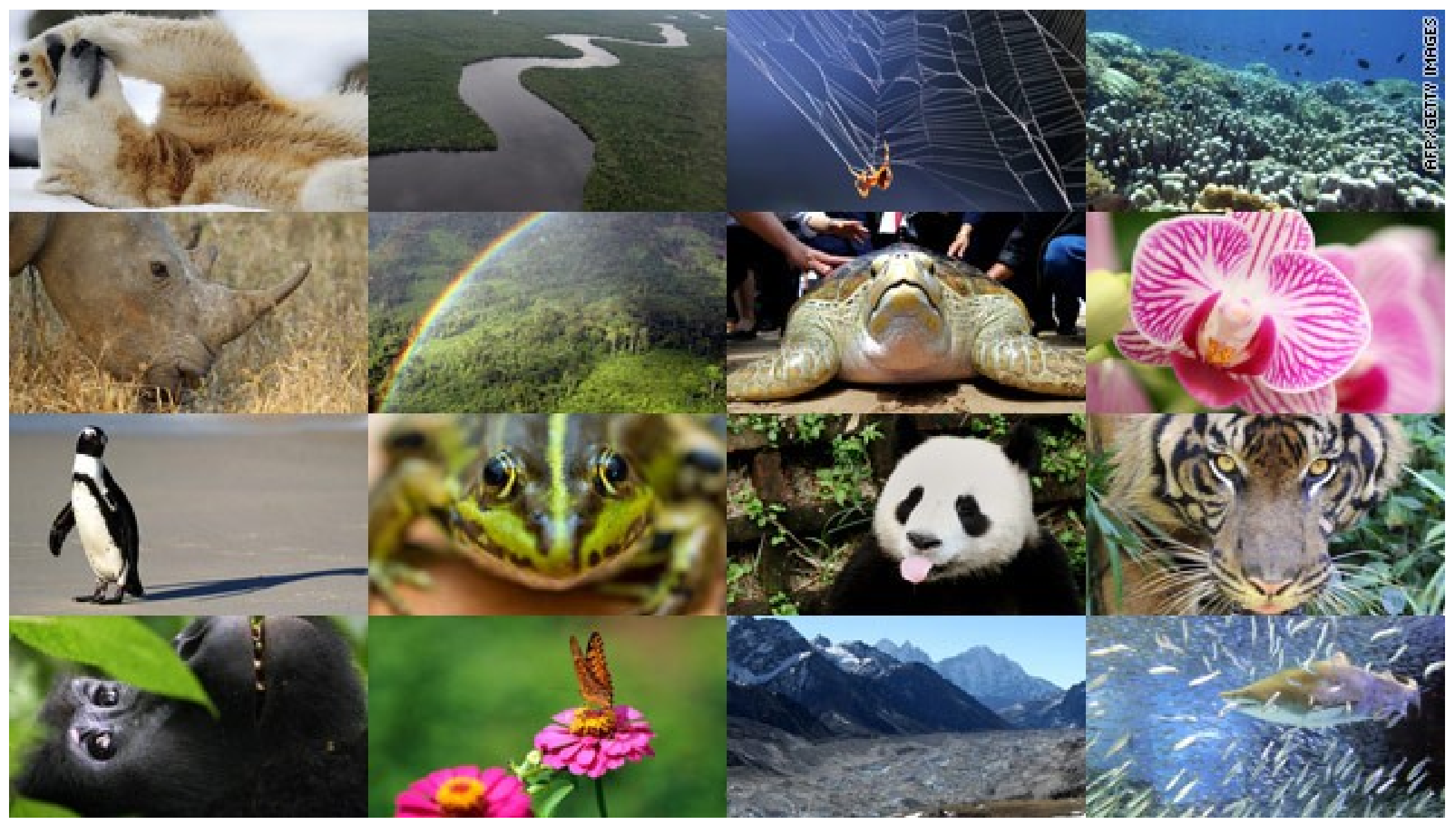




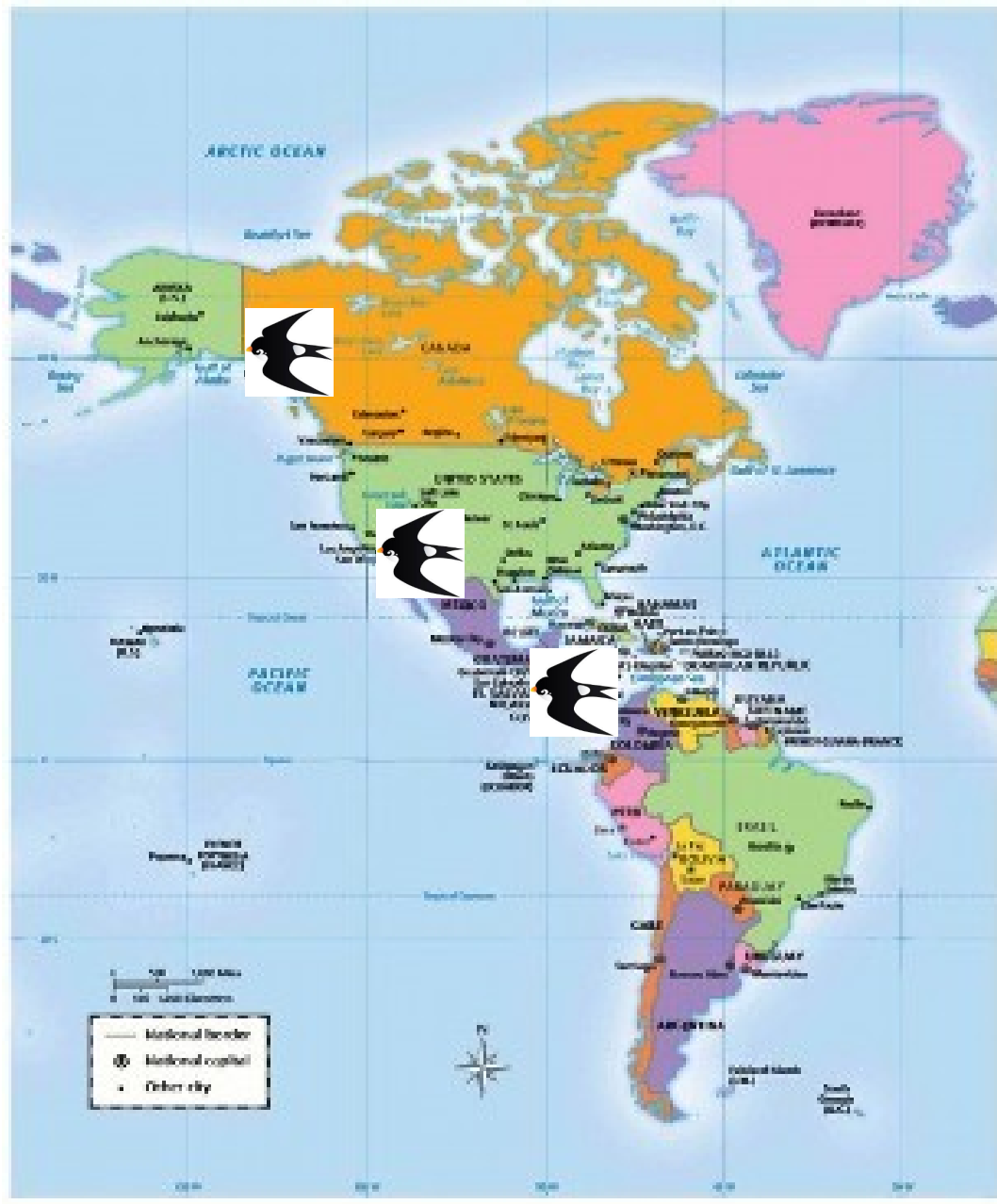

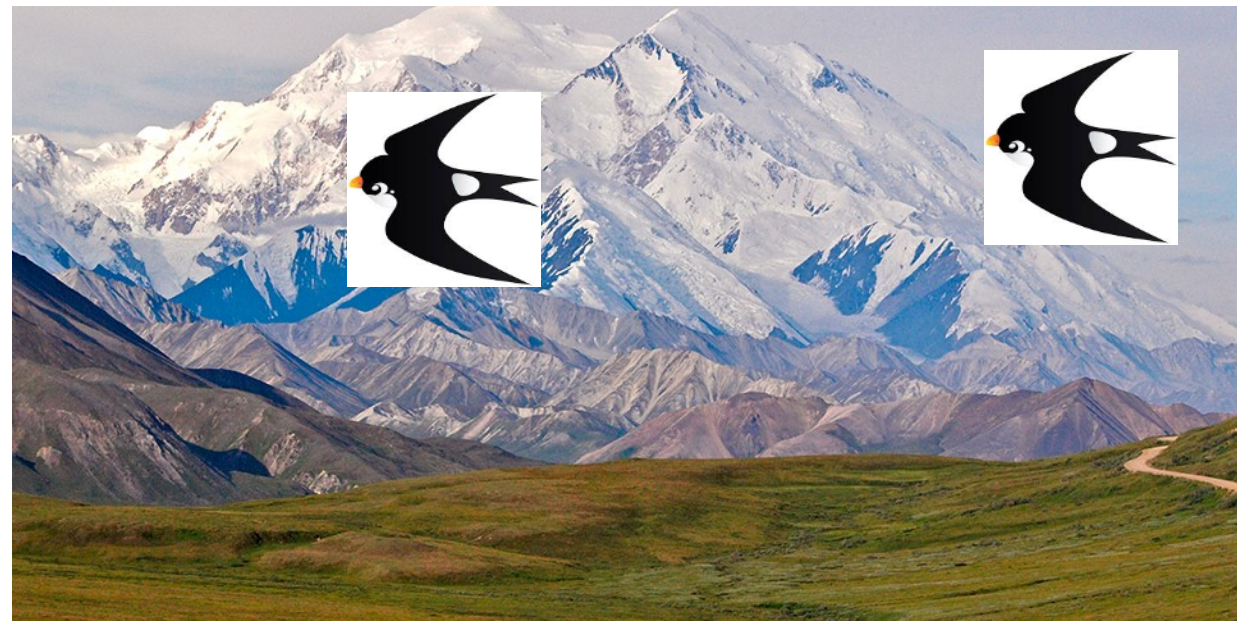

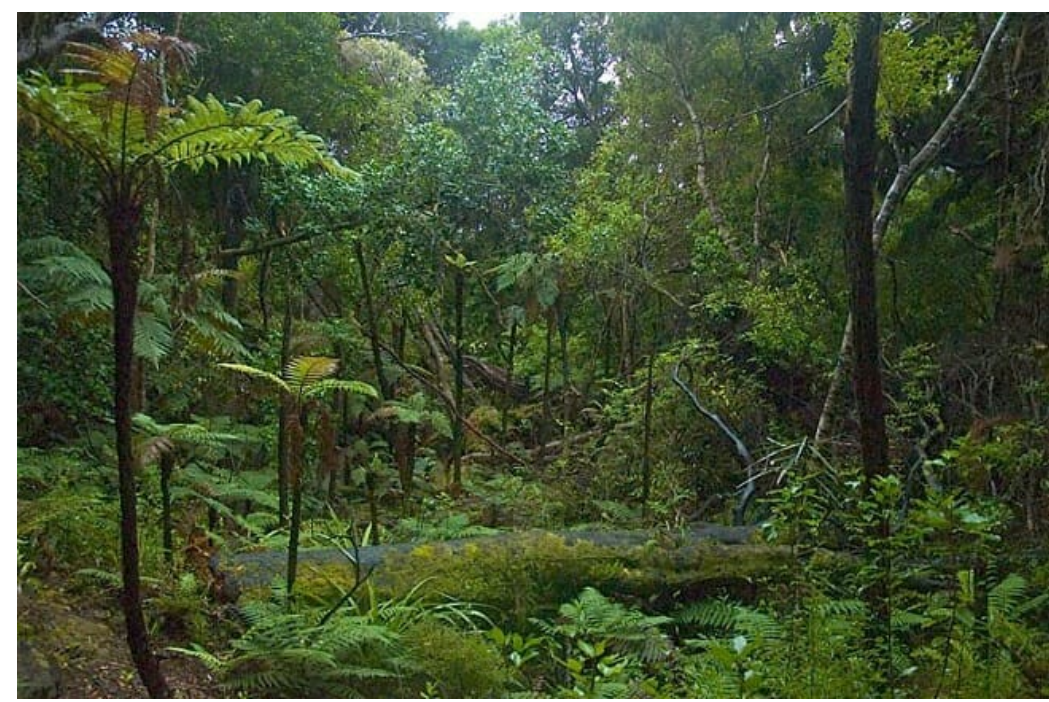




\section{What is a Cline?}

- Bergmann's Rule

- Allen's Rule

- Gloger's Rule

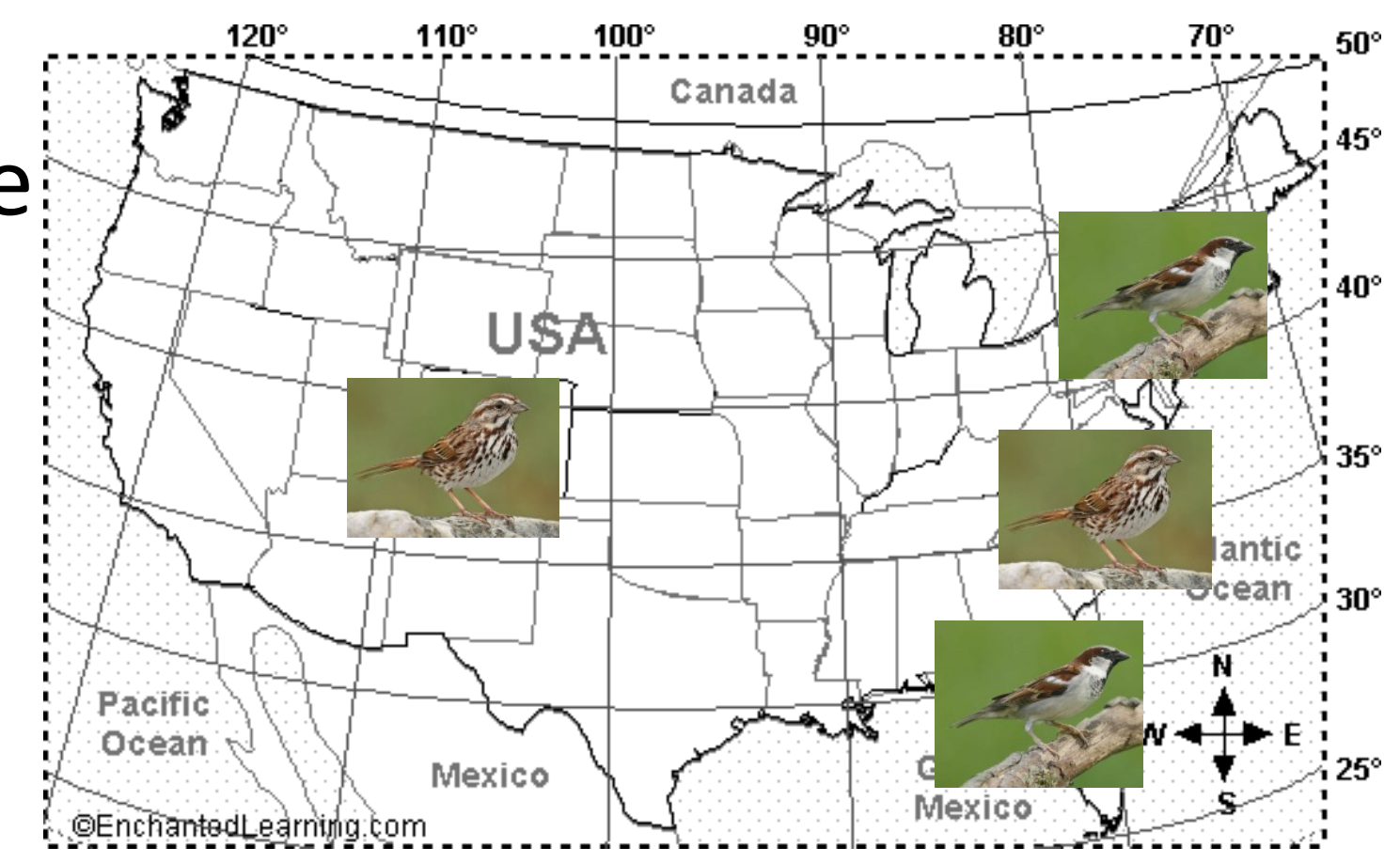




\section{Bergmann's Rule}

\section{Allan's Rule}

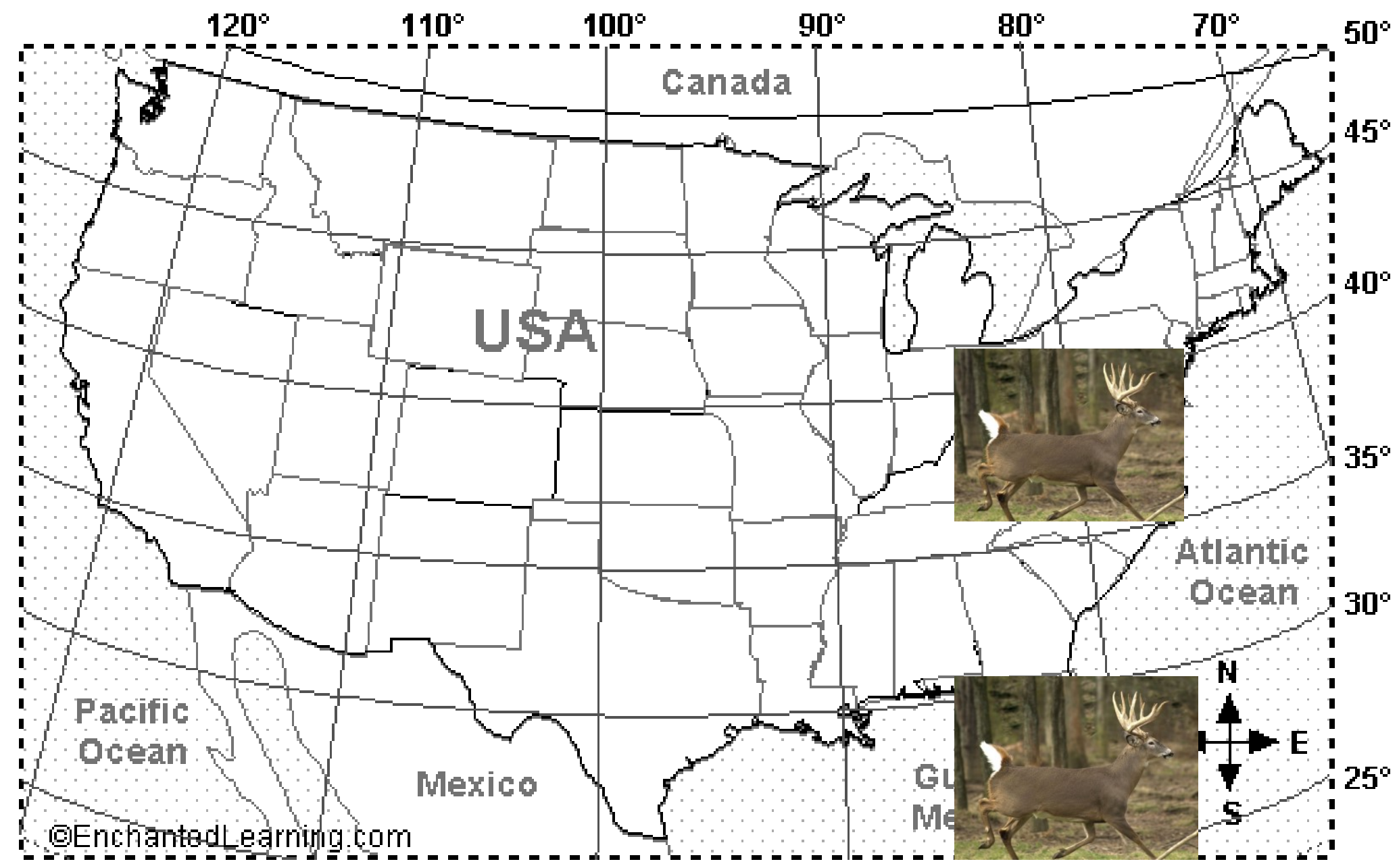




\section{Why Not Altitude}

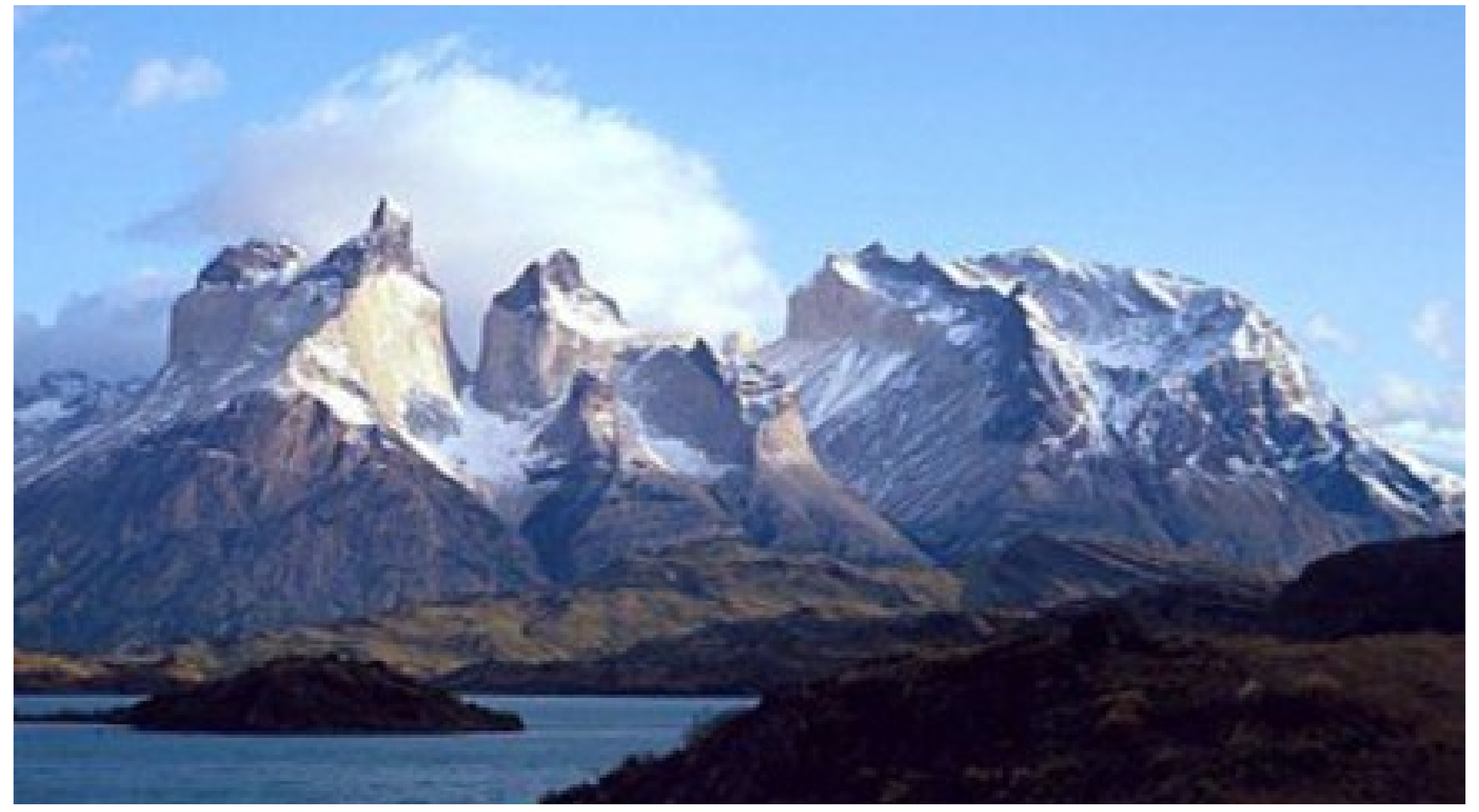




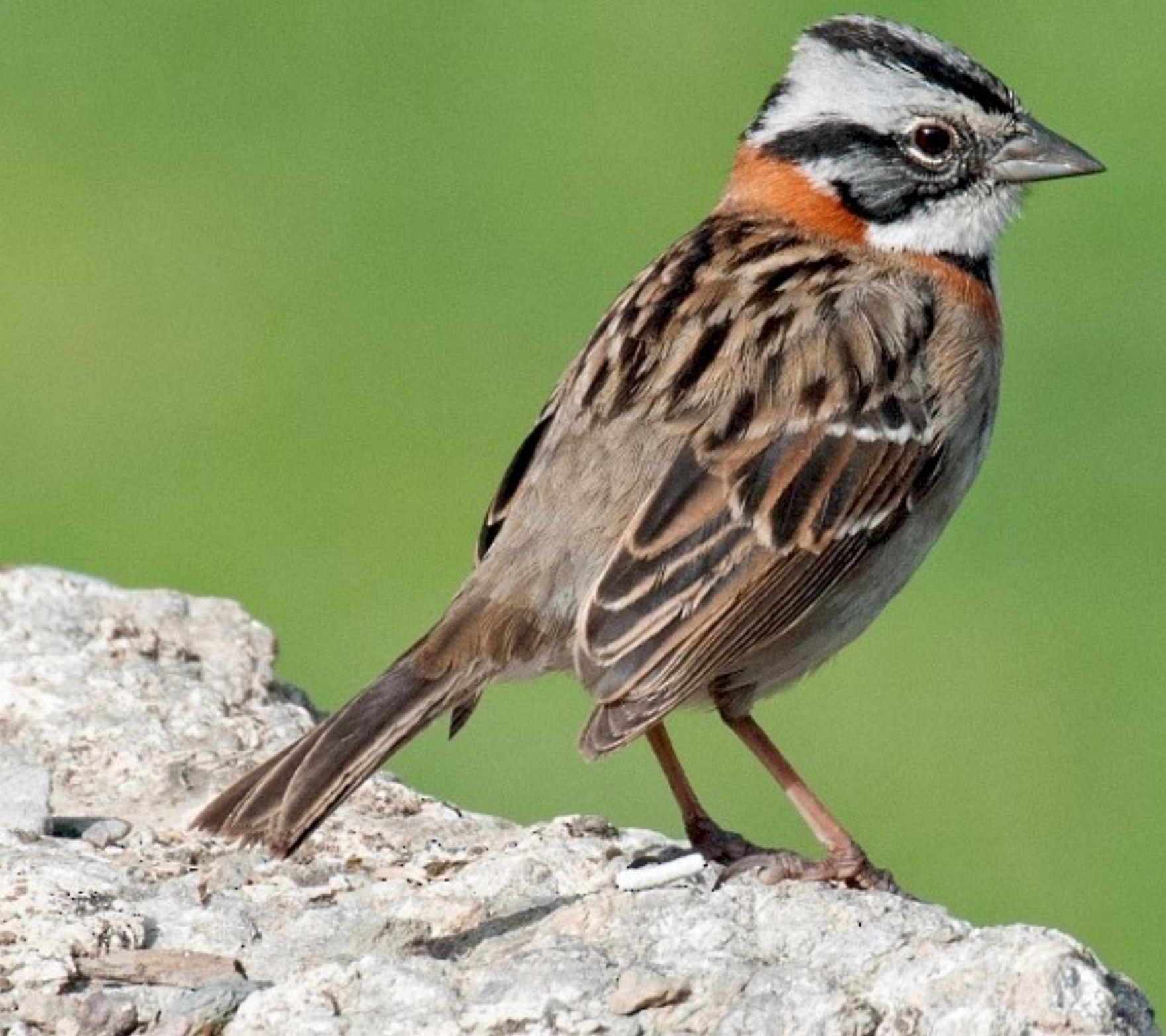




\section{Why the Rufous-Collared Sparrow}

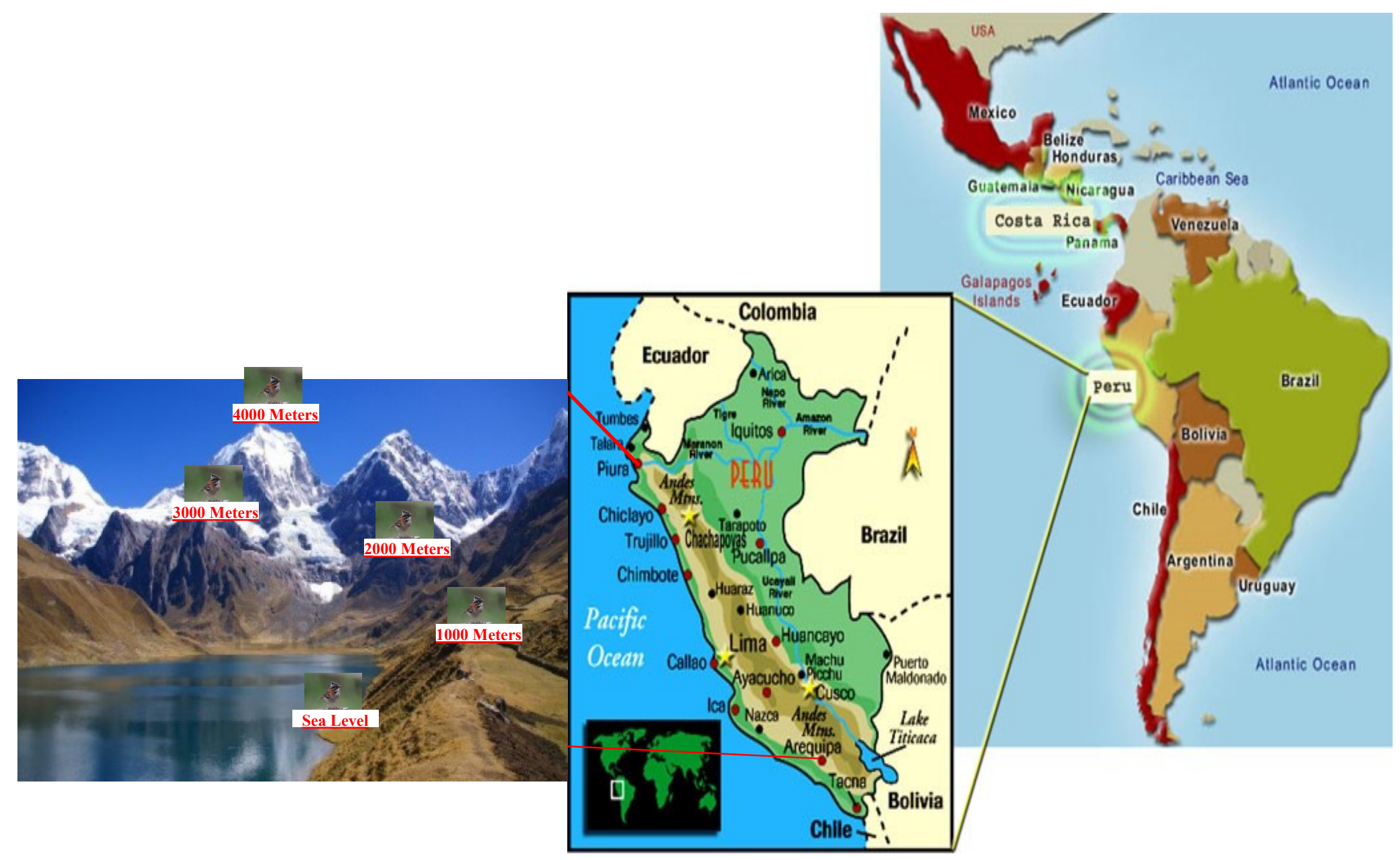




\section{Methods}

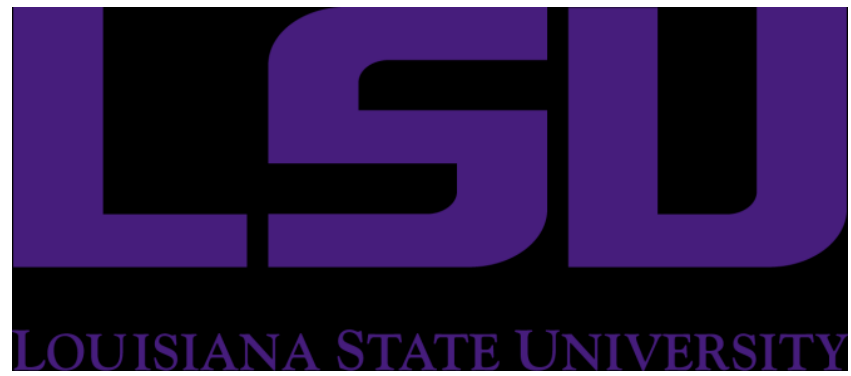

- Tarsometatarsi (mm)

- Mass (g)

- 120 males

- 57 females

- 17 unknown
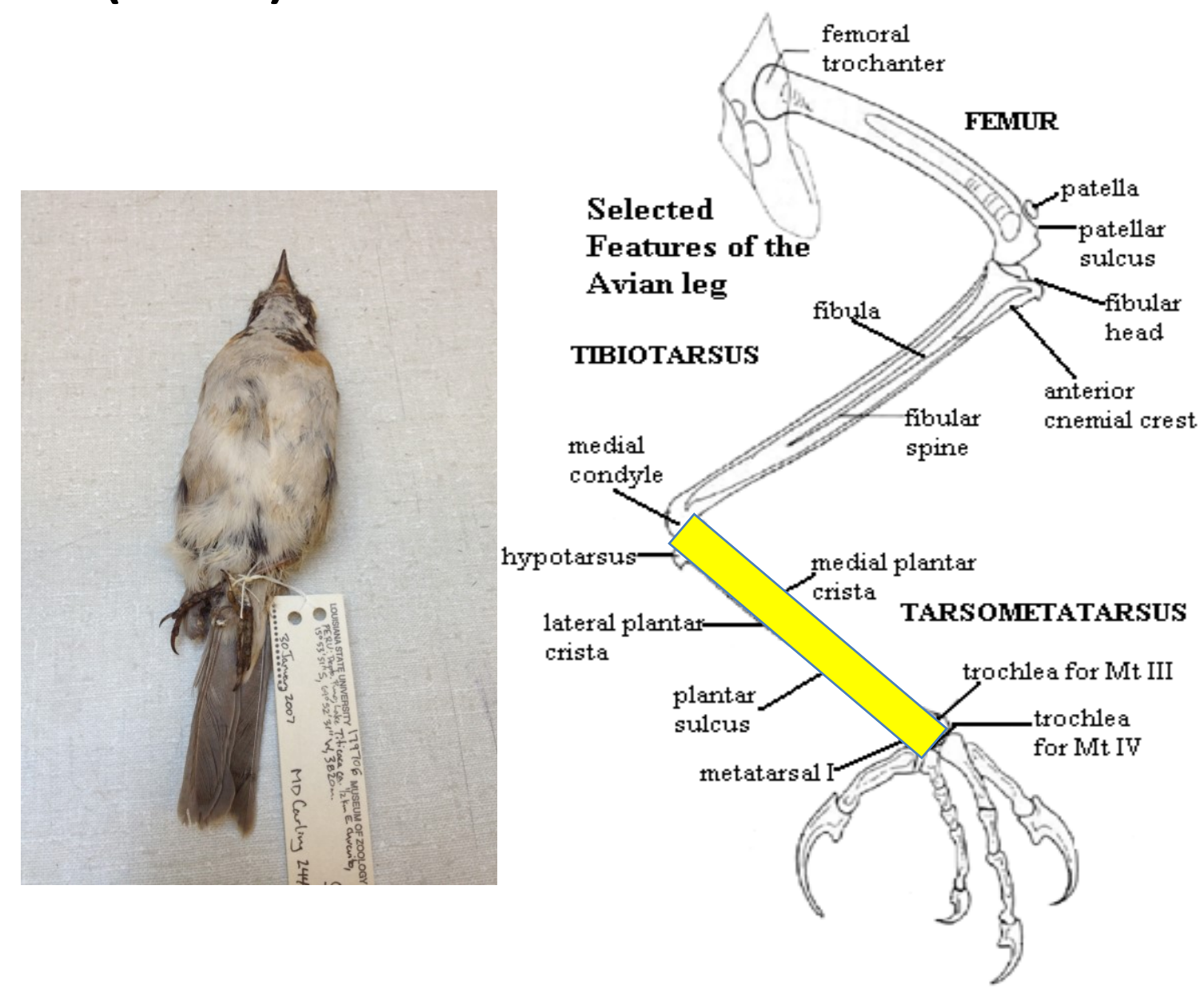


\section{Bergmann's Rule}

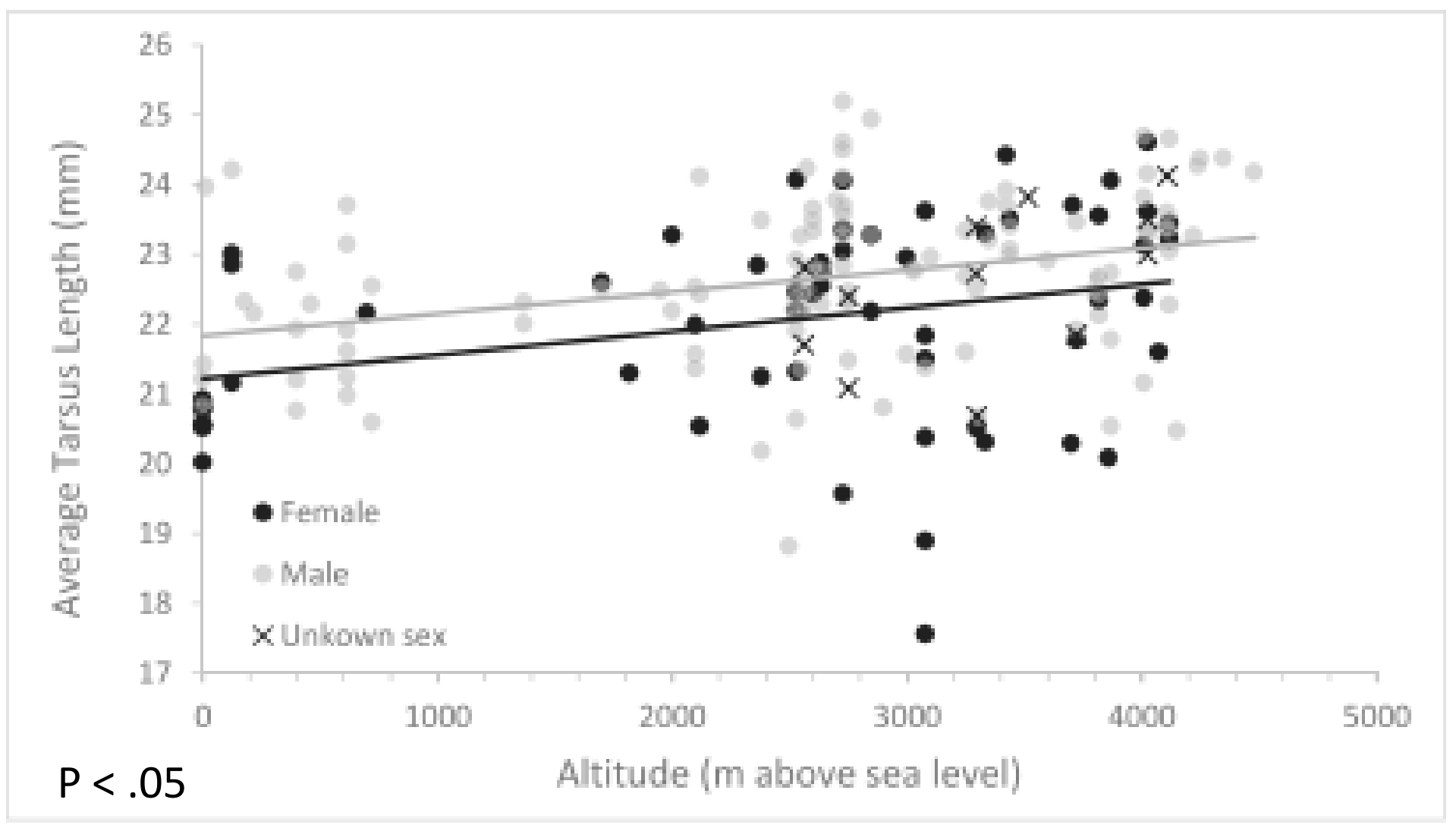




\section{Allan's Rule}

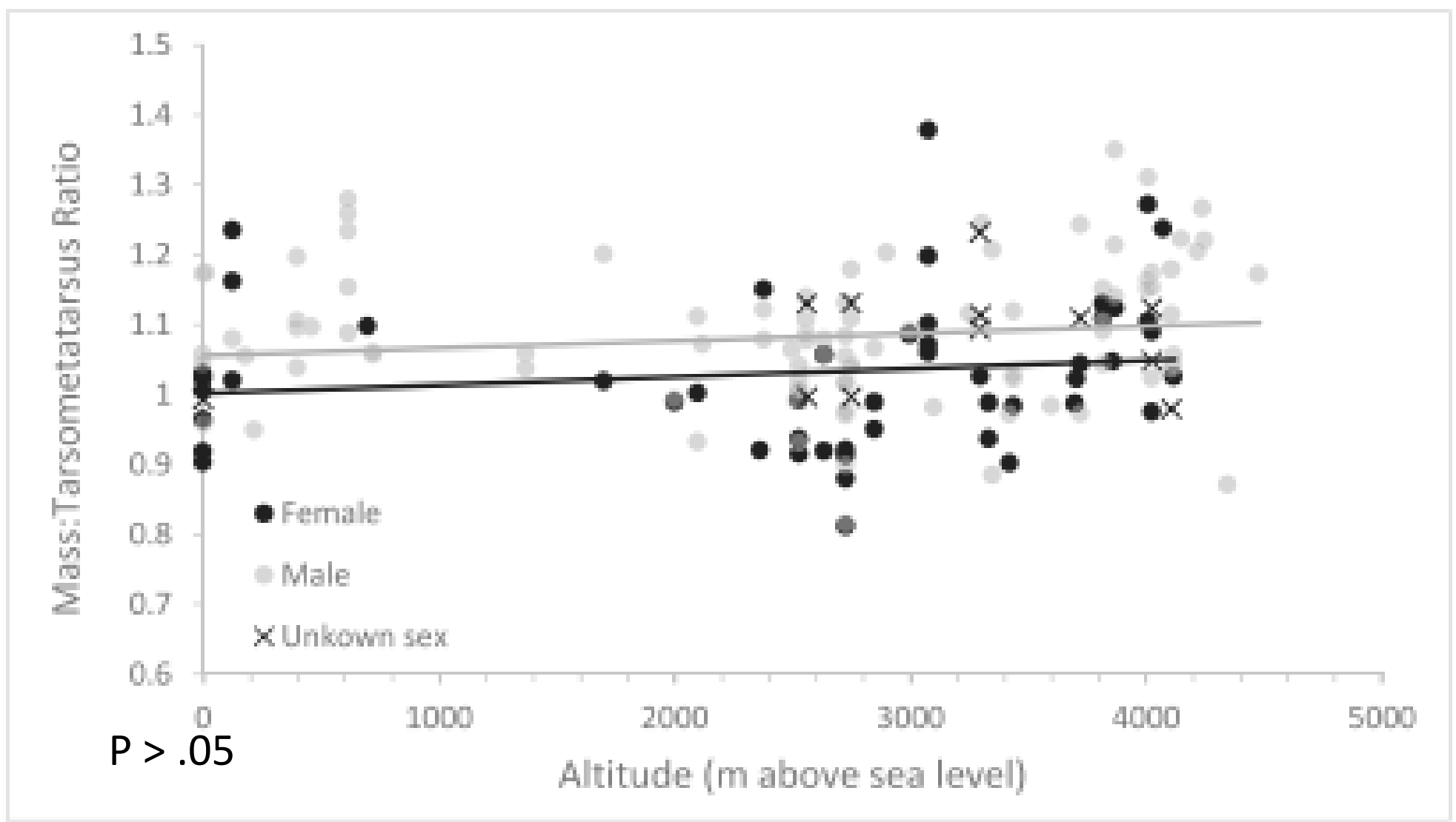




\section{Conclusion}

- Size change = significant

- Appendage size change $\neq$ significant

- Males and females = same 


\section{Bergmann's rule}

- Supports Geist 1987

- $0.33 \mathrm{~mm}$ per $1,000 \mathrm{~m}$ of altitude

- alternative strategies

- Insulation

- adjusting metabolic rate

- Suggestions

- No migration

- Temperature change 


\section{Allen's rule}

- body weight unaffected by altitude

- Behavior

- Double scratch

- $\operatorname{Leg}=$ heat sink

- Put against body 


\section{Acknowledgment}

- Dr. James Van Remsen

- Dr. Jed Burtt

- Dr. Ramon Carreno

- Dr. Dustin Reichard

- Louisiana State University Museum of Natural History

- Wilson Journal of Ornithology 